\title{
Procurement and Initial Characterization of Alloy 230 and CMS Alloy 617
}

Terry C. Totemeier Weiju Ren

May 2006

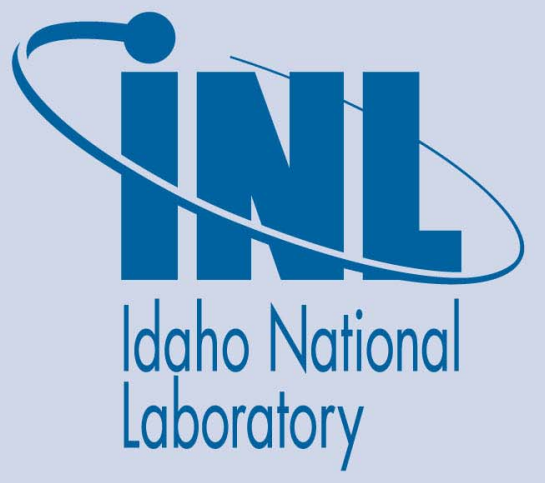

The INL is a U.S. Department of Energy National Laboratory operated by Battelle Energy Alliance 
INL/EXT-06-11290

\title{
Procurement and Initial Characterization of Alloy 230 and CMS Alloy 617
}

\author{
Terry C. Totemeier
}

Weiju Ren ${ }^{\text {b }}$

${ }^{\mathrm{b}}$ Oak Ridge National Laboratory

May 2006

\section{Idaho National Laboratory \\ Idaho Falls, Idaho 83415}

Prepared for the

U.S. Department of Energy

Office of Nuclear Energy

Under DOE Idaho Operations Office

Contract DE-AC07-05ID14517 


\title{
Procurement and Initial Characterization of Alloy 230 and CMS Alloy 617
}

\author{
INL/EXT-06-11290
}

May 2006

Approved by

George O. Hayner

Kevan D. Weaver
Date

Date

\section{Disclaimer}

This information was prepared as an account of work sponsored by an agency of the U.S. Government. Neither the U.S. Government nor any agency thereof, nor any of their employees, makes any warranty, express or implied, or assumes any legal liability of responsibility for the accuracy, completeness, or usefulness of any information, apparatus, product, or process disclosed, or represents that its use would not infringe privately owned rights. References herein to any specific commercial product, process, or service by trade name, trademark, manufacturer, or otherwise, does not necessarily constitute or imply its endorsement, recommendation, or favoring by the U.S. Government or any agency thereof. The views and opinions of authors expressed herein do not necessarily state or reflect those of the U.S. Government or agency thereof.

Prepared by the Idaho National Laboratory

P.O. Box 1625

Idaho Falls, Idaho 83415

Managed by Battelle Energy Alliance, LLC

For the U.S. Department of Energy

Under contract DE-AC07-05ID14517 


\begin{abstract}
Material for initial testing of alloy 230 and a controlled-chemistry variant of alloy 617 has been procured in the form of plates. Alloy 230 plate $3 / 4$ inch thick was commercially procured from Haynes International, and 2-inch thick CCA 617, an existing controlled-chemistry variant of alloy 617, was obtained from Alstom Power through the ultra-supercritical fossil energy program. This report describes the procurement of these plates and their characteristics in terms of vendor-supplied chemistry and mechanical properties. Further detailed characterization tests are planned for this fiscal year, and this report will be updated in September 2006 to include the results of these tests.
\end{abstract}


This page intentionally left blank. 


\section{Contents}

Abstract iii

Acronyms vii

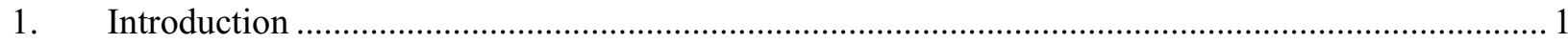

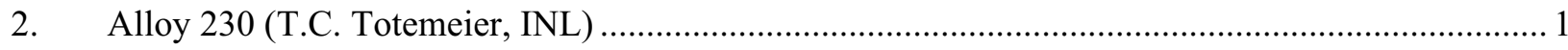

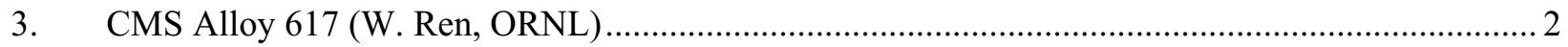

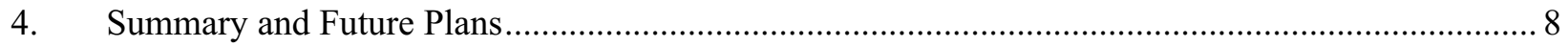

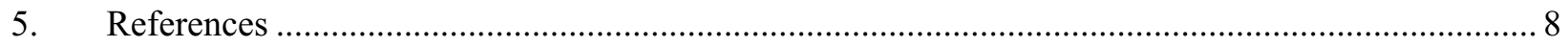

\section{Figures}

Figure 1. Comparison of CCA 617 and the average alloy 617 creep strength in Larson-Miller Parameter. 4

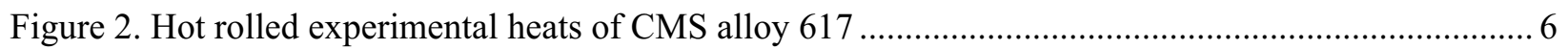

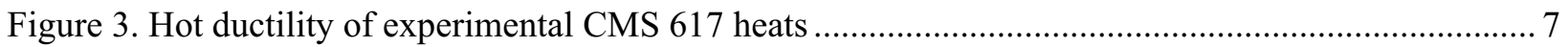

\section{Tables}

Table 1. Chemical composition of alloy 230 plate, Haynes International heat number 830557896 ......... 1

Table 2. Chemical compositions of the alloy 617 heats (wt.\%)......................................................... 3

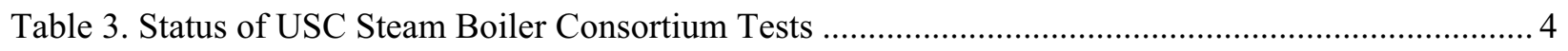

Table 4. Summary of the experimental CMS 617 heat compositions.................................................. 5 
This page intentionally left blank. 


\section{Acronyms}

ASM American Society of Mechanical Engineers

ASTM American Society for Testing and Materials

CMS controlled material specification

DOE Department of Energy

FY fiscal year

Gen IV Generation IV

INL Idaho National Laboratory

MRC Materials Review Committee

NGNP Next Generation Nuclear Plant

ORNL Oak Ridge National Laboratory

USC Ultra Supercritical Steam Boiler

VHTR Very High Temperature Gas-Cooled Reactor 
This page intentionally left blank. 


\section{Procurement and Initial Characterization of Alloy 230 and CMS Alloy 617}

\section{Introduction}

The Generation IV (GenIV) Very High Temperature Gas-Cooled Reactor concept (VHTR) is a helium-cooled, graphite-moderated, thermal neutron spectrum nuclear reactor for demonstrating the thermodynamically efficient production of electricity and hydrogen without production of greenhouse gases. The demonstration-scale version of this reactor is referred to as the Next Generation Nuclear Plant (NGNP). For efficient production of hydrogen using a thermochemical cycle driven by nuclear process heat, the reactor coolant outlet temperature must be as high as reasonably achievable, ideally in excess of $950^{\circ} \mathrm{C}$. Such temperatures will significantly challenge the temperature capability of existing construction materials, particularly for metallic materials directly exposed to the coolant.

The two primary candidate alloys being considered for qualification for use in the NGNP are nickel alloys 617 and 230. Alloy 617 is the primary candidate due to the significant data that already exists; alloy 230 is considered the primary backup alloy because it has similar creep resistance, but without the potentially undesirable alloying additions of $\mathrm{Co}, \mathrm{Al}$, and $\mathrm{Ti}$ (Co is activated under irradiation, while $\mathrm{Al}$ and Ti form internal oxides and increase the difficulty of solid-state joining processes, such as brazing and diffusion bonding). Considerable experimental work is required for qualification of these two alloys. Large plates of both alloys have been procured to provide significant common material for test programs underway at the Idaho National Laboratory (INL) and the Oak Ridge National Laboratory (ORNL). In addition, work has been performed on the development of a controlled material specification (CMS) variant of alloy $617^{[1]}$ with the objectives of (1) reducing the heat-to-heat scatter observed for standard chemistry alloy 617 and (2) selecting an alloy chemistry within the existing specification with the best combination of properties for VHTR applications. This report describes the procurement and initial characterization of the two alloys.

\section{Alloy 230 (T.C. Totemeier, INL)}

A plate of nickel alloy 230 was procured from Haynes International (Kokomo, IN) and received in December 2005. The plate conforms to American Society of Testing and Materials (ASTM)/American Society of Mechanical Engineers (ASME) specification B 435, UNS\# N06230, and is $0.750 \times 45 \times 100$ $\mathrm{in}^{3}$ in dimension. The heat number is 830557896 ; the chemical composition of the plate supplied on the certificate sheets is given in Table 1. The certified grain size and hardness is ASTM 4.5 and 92 HRB, respectively. The certified room temperature tensile properties are $52.5 \mathrm{ksi} 0.2 \%$ offset yield strength, 119 ksi ultimate tensile strength, $46 \%$ ductility, and $43 \%$ reduction in area.

Idaho National Laboratory characterization of the plate is underway. The plate has been sectioned into smaller pieces with dimensions of 0.750 " x 10 " x 15 "; specimens for room and elevated-temperature tensile testing and room-temperature Charpy impact testing are currently being machined. Pieces have been supplied to ORNL for baseline creep testing.

Table 1. Chemical composition of alloy 230 plate, Haynes International heat number 830557896

\begin{tabular}{|l|c|c|c|c|c|c|c|c|c|c|c|c|c|c|c|}
\hline Element & Ni & Cr & W & Fe & Mo & Co & Mn & Si & C & Al & Ti & Cu & P & S & B \\
\hline Wt \% & Bal & 22.43 & 13.91 & 1.34 & 1.34 & 0.21 & 0.53 & 0.37 & 0.11 & 0.29 & $<0.01$ & 0.04 & 0.005 & $<0.002$ & 0.004 \\
\hline
\end{tabular}




\section{CMS Alloy 617 (W. Ren, ORNL)}

The fiscal year (FY) 2006 activities in procuring and characterizing CMS alloy 617 are a continuation of the FY 2005 efforts in developing a CMS for nuclear applications. The FY 2005 efforts were focused on collecting and analyzing historical data generated from commercial heats produced to the ASTM/ASME standard specifications of Alloy 617. As a result of those efforts, a tentative CMS 617 specification was suggested in an ORNL report ${ }^{[1]}$ for further studies on manufacturability as well as other desired effects through experiments. A workshop with major high alloys manufacturers was also suggested by the NGNP Materials Review Committee (MRC) to discuss the manufacturability issues of the proposed CMS 617.

The workshop was held at ORNL during the first month of FY 2006. Participants included three major manufacturers of alloy 617, i.e., Special Metals, ThyssenKrupp VDM, and Haynes International, as well as personnel from INL and ORNL. The manufacturers pointed out that although the refinement efforts for Gen IV applications was restricted within the ASTM/ASME specifications, it could still be considered as a development of a new specification from the manufacturing view point. After discussion, the manufacturers recommended adjustments to the chemistry of the tentative CMS 617 to avoid potential material processing difficulties, mainly in hot and cold workability of the material. Meanwhile, computational modeling conducted by both ORNL and Special Metals warned of possible sigma phase formation from the tentative CMS 617 chemistry and suggested experimental investigation.

To address these concerns, several 10-1b heats of various adjusted chemistries of the alloy were designed and produced at ORNL for experimental investigation. Microanalyses of those small heats showed no indication of widespread sigma existence, ruling out concerns about potential property degradation due to massive sigma phase formation, especially after continued high-temperature processing that is needed in commercial heats. In the investigation of hot workability, ingot production, chemistry analysis, specimen machining, and testing of the first experimental 10-lb heat, designated as "GenIV-1", were completed in January of 2006. Analysis of the testing results suggested that the content of sulfur should be further controlled with the addition of magnesium. Adjustments were made accordingly in later heats for further study. Although the experimental cycle of the GenIV-1 heat was extremely fast on the normal alloy development time scale, by January of 2006 it seemed unlikely that satisfactory results could possibly be achieved within the deadline to meet the deliverable requirement of FY 2006. As pointed out in the last paragraph of Section 5.2, "Future Work," in the FY 2005 ORNL report $^{[1]}$, when possible lengthy iterations of metallurgical experiments to investigate the effects of the variations in $\mathrm{Al}, \mathrm{Ti}, \mathrm{C}, \mathrm{Mo}, \mathrm{Co}, \mathrm{B}$, and $\mathrm{N}$ on properties of the alloy were discussed, a managerial decision had to be made based on the required timeframe and funding availability at a certain time of the development. The result from the Gen IV-1 heat indicated that it was the time for such a managerial decision to be made..

Based on the situation, a suggestion was made by INL that while the efforts in the experimental small heats was underway, procurement and initial characterization of CMS 617 should have an alternate plan. It was suggested that an existing chemistry-controlled variant of alloy 617, designated as CCA 617, be procured and characterized for Gen IV reactor working conditions. It was considered that this alternate plan would not only enable meeting the FY 2006 deliverable requirement, but also provide more choices in the material selection process. The CCA 617 was developed for the Ultra Supercritical Steam Boiler Project (USC Project) with a target steam working temperature of $760^{\circ} \mathrm{C}$, and the material has been under investigation for the intended application conditions at ORNL. Preliminary results from the USC Project indicated improved creep strength around the intended USC working temperature range, but showed a trend of merging back into the standard strength at higher temperatures. More testing in the higher temperature range applicable to Gen IV reactor working conditions would be necessary if the material was considered for the Gen IV program. 
Inquiry into acquisition of CCA 617 revealed that only one heat of the material had ever been produced. Negotiation was then conducted with the USC Project for supplying CCA 617 for the GenIV Program $^{[2]}$. Although the USC Project is a Department of Energy (DOE)-sponsored program, the State of Ohio and some companies in the private sector have also provided resources and/or funds; therefore proprietary issues were raised during the negotiation. Agreement was eventually reached that Alstom Power (formerly Combustion Engineering) would provide the CCA 617 material under the USC Project at no cost to the Gen IV Program to generate data and fill data gaps for improved properties verification and ASME codification. In return, the Gen IV Program should provide Alstom Power with the data generated at no cost for the USC Project or other applications.

Based on the agreement, a plate of $2 \times 12 \times 39 \mathrm{in}^{3}$ CCA 617 was delivered to ORNL in mid April. The plate was produced by ThyssenKrupp VDM with chemistry adjustments within the ASTM/ASME specification. The composition of the material is given in Table 2, including the aim value (It would be more appropriate to use steel making jargon in this report.) ranges and the product analysis results. For comparison purpose, the ASTM/ASME specification chemistry is also listed. The adjustments prescribed for the CCA 617 relative to the ASTM/ASME specification are marked in red. The actual CCA 617 product composition is marked in blue.

Table 2. Chemical compositions of the alloy 617 heats (wt.\%)

\begin{tabular}{|c|c|c|c|c|c|c|c|c|}
\hline Heat & $\mathbf{N i}$ & $\mathrm{Cr}$ & Co & Mo & $\mathbf{F e}$ & Mn & Al & $\mathbf{C}$ \\
\hline ASTM Max & & 24.0 & 15.0 & 10.0 & 3.0 & 1.0 & 1.5 & 0.15 \\
\hline ASTM Min & 44.5 & 20.0 & 10.0 & 8.0 & & & 0.8 & 0.05 \\
\hline CCA 617Max & & 23.0 & 13.0 & 10.0 & 1.5 & 0.3 & 1.3 & 0.08 \\
\hline CCA 617Min & Bal. & 21.0 & 11.0 & 8.0 & & & 0.8 & 0.05 \\
\hline CCA 617PA ${ }^{\mathrm{a}}$ & Bal. & 21.5 & 11.3 & 8.6 & 0.7 & 0.03 & 1.24 & 0.06 \\
\hline Heat & $\mathrm{Cu}$ & $\mathbf{S i}$ & $\mathbf{S}$ & Ti & $\mathbf{P}$ & B & $\mathbf{N}$ & $\mathbf{N b}$ \\
\hline ASTM Max & 0.5 & 1.0 & 0.015 & 0.6 & & 0.006 & & \\
\hline \multicolumn{9}{|l|}{ ASTM Min } \\
\hline CCA 617Max & 0.05 & 0.3 & 0.008 & 0.5 & 0.012 & 0.005 & 0.050 & \\
\hline CCA 617Min & & & & 0.3 & & 0.002 & & \\
\hline $\mathrm{CCA} 617 \mathrm{PA}^{\mathrm{a}}$ & 0.01 & 0.1 & $<0.001$ & 0.39 & 0.003 & 0.003 & 0.013 & 0.02 \\
\hline
\end{tabular}

a) Product analysis

Limited data on the CCA 617 generated in the USC Project are presented in Figure 1 in comparison with a curve representing average alloy 617 commercial heat behavior. Data generation status and plans under the USC Project is given in Table 3. It would be efficient if data generation activities for Gen IV Program were coordinated with those of the USC Project. However, because of the proprietary nature of the USC Project data and the involvement of the State of Ohio and other companies, negotiation for access to the data generated under the USC Project is expected to be a lengthy and difficult process. Therefore, current testing plans for CCA 617 should be based on the data requirement guidelines stipulated in the "High Temperature Metallic Materials Test Plan for Generation IV Nuclear Reactors" ${ }^{[3]}$. Discussion is underway between ORNL and INL to coordinate the details of the testing plans and activities. 


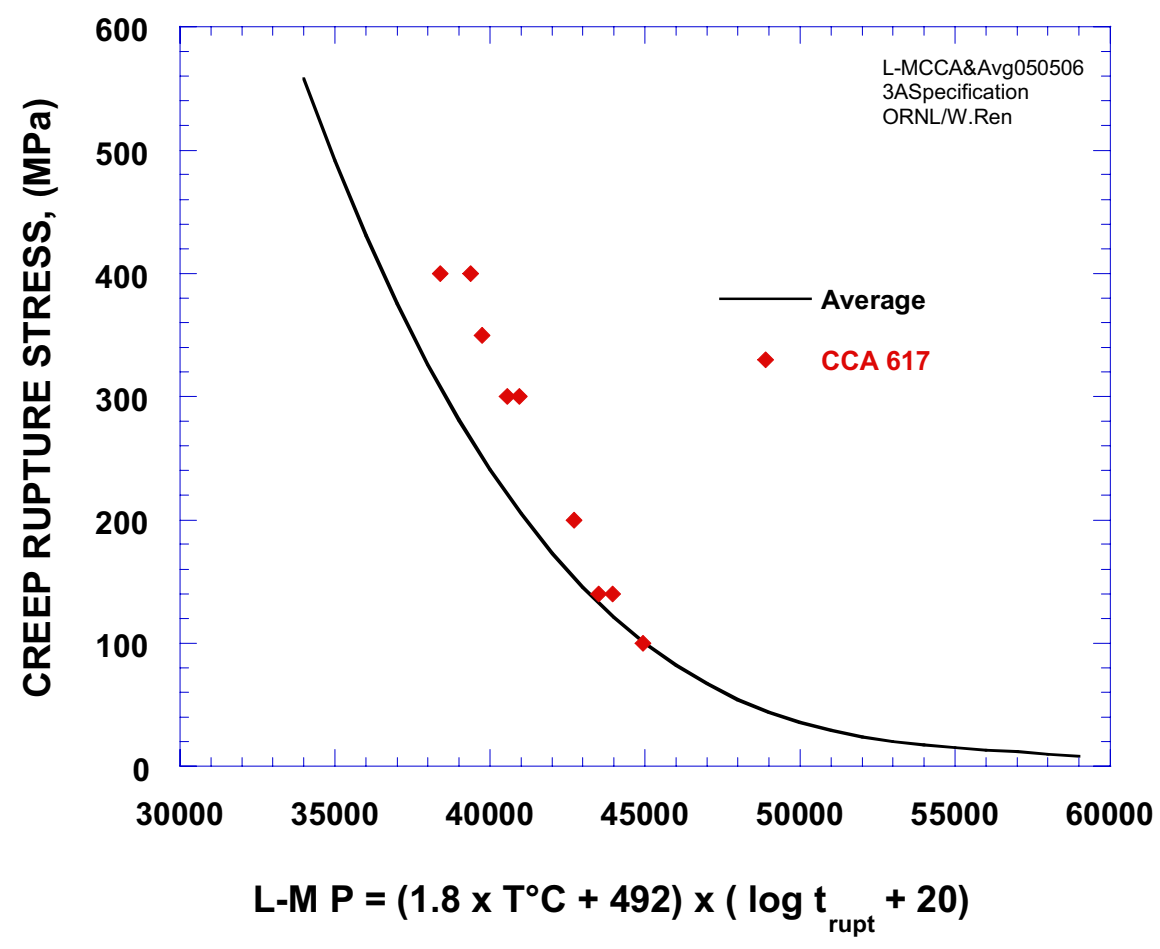

Figure 1. Comparison of CCA 617 and the average alloy 617 creep strength in Larson-Miller Parameter

Table 3. Status of USC Steam Boiler Consortium Tests

\begin{tabular}{|c|l|l|l|l|l|l|l|l|}
\hline $\begin{array}{c}\text { Temp } \\
(\mathbf{C})\end{array}$ & \multicolumn{2}{|c|}{ Stress Range (MPa) } & \multicolumn{2}{|c|}{ Estimated Life (h) } & \multicolumn{1}{c|}{$\begin{array}{c}\text { Tests } \\
\text { Completed }\end{array}$} & $\begin{array}{c}\text { Tests } \\
\text { On-going }\end{array}$ & $\begin{array}{c}\text { Longest-time } \\
\text { On-going (h) }\end{array}$ \\
\hline 650 & 400 & 200 & 1000 & 50000 & 2 & 2 & 23,000 \\
\hline 700 & 400 & 140 & 200 & 50000 & 2 & 2 & 23,000 \\
\hline 750 & 300 & 100 & 100 & 20000 & 3 & 1 & 12,000 \\
\hline 800 & 140 & 80 & 200 & 10000 & 3 & 0 & \\
\hline Planned Test Conditions & \multicolumn{5}{|c|}{ Possible Fill-in Tests } \\
\hline $\begin{array}{c}\text { Temp } \\
(\mathbf{C})\end{array}$ & $\begin{array}{c}\text { Stress } \\
(\mathbf{M P a})\end{array}$ & $\begin{array}{c}\text { Estimated } \\
\text { Life (h) }\end{array}$ & & $\begin{array}{c}\text { Temp } \\
\text { (C) }\end{array}$ & $\begin{array}{c}\text { Stress } \\
\text { (MPa) }\end{array}$ & $\begin{array}{c}\text { Estimated } \\
\text { Life (h) }\end{array}$ & \\
\hline 650 & 400 & 1000 & & 650 & 330 & 10000 & \\
\hline 650 & 350 & 8000 & & 700 & 250 & 10000 & \\
\hline 650 & 300 & 30000 & & 750 & 180 & 5000 & \\
\hline 700 & 400 & 200 & & 775 & 140 & 2000 & \\
\hline 700 & 300 & 2000 & & 800 & 80 & 10000 & \\
\hline 700 & 200 & 30000 & & 800 & 70 & 20000 & \\
\hline 750 & 300 & 100 & & 850 & 80 & $?$ & \\
\hline 750 & 200 & 1500 & & & & & \\
\hline 750 & 140 & 8000 & & & & & & \\
\hline 750 & 100 & 15000 & & & & & & \\
\hline 800 & 140 & 200 & & & & & \\
\hline
\end{tabular}


While the acquisition of CCA 617 plate was being negotiated, several more experimental CMS compositions were designed and ingots made for testing and analysis. A summary of the experimental CMS 617 heats designed to date is given in Table 4. To save cost and time, some of the heat compositions were not actually produced but used for computational modeling for phase prediction to provide guidance for casting selection. Based on the modeling and analysis, another three ingots, with the compositions of GenIV-5, GenIV-6, and GenIV-7 were cast in addition to GenIV-1. The GenIV-6 heat had the average composition of 13 commercial heats that had the magnesium addition to control sulfur concentration. The GenIV-7 heat had a composition refinement based on the inputs from the manufacturers and analysis of the previous experiments. The GenIV-5 heat was produced as an alternative backup. The GenIV-6 and GenIV-7 heats were further processed. Visual observation after hot rolling indicates that hot workability of the two heats is comparable, with the GenIV-7 having less surface defects, as presented in Figure 2.

Table 4. Summary of the experimental CMS 617 heat compositions

\begin{tabular}{|l|c|c|c|c|c|c|c|c|}
\hline \multicolumn{1}{|c|}{ Heat } & Ni & Cr & Co & Mo & Fe & Mn & Al & C \\
\hline GenIV-1 & Bal. & 22.0 & 15.0 & 8.0 & 2.0 & 1.0 & 1.3 & 0.09 \\
\hline GenIV-1PA & 50.66 & 21.71 & 14.80 & 7.91 & 2.05 & 0.97 & 1.21 & 0.12 \\
\hline GenIV-2 & Bal. & 20.0 & 15.0 & 10.0 & 2.0 & 1.0 & 1.3 & 0.09 \\
\hline GenIV-3 & Bal. & 22.0 & 15.0 & 10.0 & 2.0 & 1.0 & 1.3 & 0.09 \\
\hline GenIV-4 & Bal. & 24.0 & 15.0 & 10.0 & 2.0 & 1.0 & 1.3 & 0.09 \\
\hline GenIV-5 & Bal. & 22 & 15 & 8 & 2.0 & 1.0 & 1.30 & 0.09 \\
\hline GenIV-5PA & Bal. & 21.66 & 14.92 & 8.03 & 2.03 & 0.96 & 1.32 & 0.107 \\
\hline GenIV-6 & Bal. & 22 & 12.5 & 8.9 & 0.4 & 0.0 & 1.06 & 0.07 \\
\hline GenIV-6PA & Bal. & 21.68 & 12.54 & 8.88 & 0.43 & $<0.01$ & 1.15 & 0.07 \\
\hline GenIV-7 & Bal. & 22 & 15 & 10 & 2.0 & 1.0 & 1.30 & 0.09 \\
\hline GenIV-6PA & Bal. & 21.65 & 14.97 & 9.95 & 2.03 & 0.94 & 1.35 & 0.09 \\
\hline & $\mathbf{C u}$ & $\mathbf{S i}$ & $\mathbf{S}$ & $\mathbf{T i}$ & $\mathbf{P}$ & $\mathbf{B}$ & $\mathbf{N}$ & $\mathbf{M g}$ \\
\hline Heat & 0.1 & 0.2 & 0.004 & 0.5 & 0.005 & 0.004 & 0.02 & - \\
\hline GenIV-1PA & $<0.01$ & $<0.01$ & 0.011 & 0.66 & 0.004 & 0.005 & 0.075 & - \\
\hline GenIV-2 & 0.1 & 0.2 & 0.004 & 0.5 & 0.005 & 0.004 & 0.02 & - \\
\hline GenIV-3 & 0.1 & 0.2 & 0.004 & 0.5 & 0.005 & 0.004 & 0.02 & - \\
\hline GenIV-4 & 0.1 & 0.2 & 0.004 & 0.5 & 0.005 & 0.004 & 0.02 & - \\
\hline GenIV-5 & 0.1 & 0.2 & $<0.001$ & 0.50 & 0.003 & 0.004 & 0.020 & 0.035 \\
\hline GenIV-5PA & $<0.01$ & 0.01 & 0.005 & 0.62 & $<0.002$ & 0.0047 & 0.028 & $<0.01$ \\
\hline GenIV-6 & 0.08 & 0.1 & $<0.004$ & 0.36 & 0.003 & 0.003 & 0.016 & 0.035 \\
\hline GenIV-6PA & $<0.01$ & 0.01 & 0.004 & 0.49 & $<0.002$ & 0.0004 & 0.030 & 0.01 \\
\hline GenIV-7 & 0.1 & 0.2 & $<0.001$ & 0.50 & 0.003 & 0.004 & 0.020 & 0.035 \\
\hline GenIV-6PA & $<0.01$ & 0.01 & 0.004 & 0.63 & $<0.002$ & 0.0043 & 0.039 & 0.01 \\
\hline PA & & & & & & & \\
\hline
\end{tabular}

$\mathrm{PA}=$ product analysis 


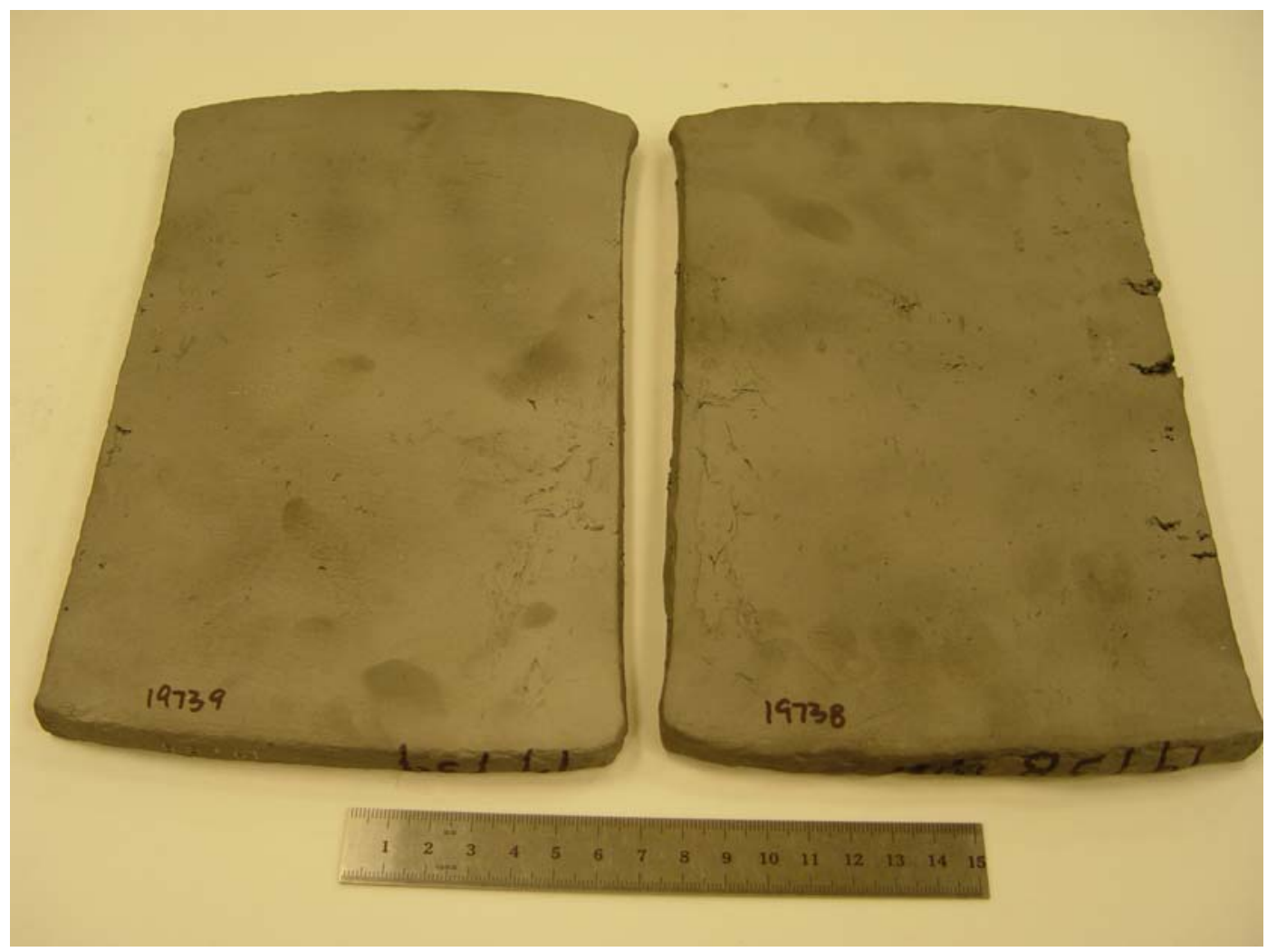

Figure 2. Hot rolled experimental heats of CMS alloy 617 (GenIV-7 heat is on the left and GenIV-6 is on the right)

Results of hot ductility testing are presented in Figure 3. The testing was conducted using a Gleeble machine at a loading rate of $25.4 \mathrm{~mm} / \mathrm{s}(1 \mathrm{inch} / \mathrm{s})$. The results also indicate that GenIV-6 and GenIV-7 heats are comparable at temperatures up to $1170^{\circ} \mathrm{C}$. However, above $1200^{\circ} \mathrm{C}$, hot ductility of the GenIV7 heat exhibits a dramatic plummet to zero. Because the temperature range around $1200^{\circ} \mathrm{C}$ is usually used for hot processing of the material, the observed sudden drop may suggest a potential hot working problem of the heat. Furthermore, if the hot working problem of the GenIV-7 heat does exist, the preliminary results suggest that a commercial order to the ASTM/ASME specification, if it happens to have the GenIV-7 conditions, may also have the same hot working problem. At present, microstructural characterization of the fracture surfaces is underway to investigate possible formation of low-melting phases. As pointed out in the FY 2005 ORNL report ${ }^{[1]}$, the significant scatter observed in existing properties data might be attributed to variations within the ASTM/ASME specifications. Therefore, identifying and excluding those composition sub-ranges might help the objective of reducing the heat-toheat scatter observed for standard chemistry Alloy 617, which is the first goal set in the FY 2005 ORNL report ${ }^{[1]}$. 


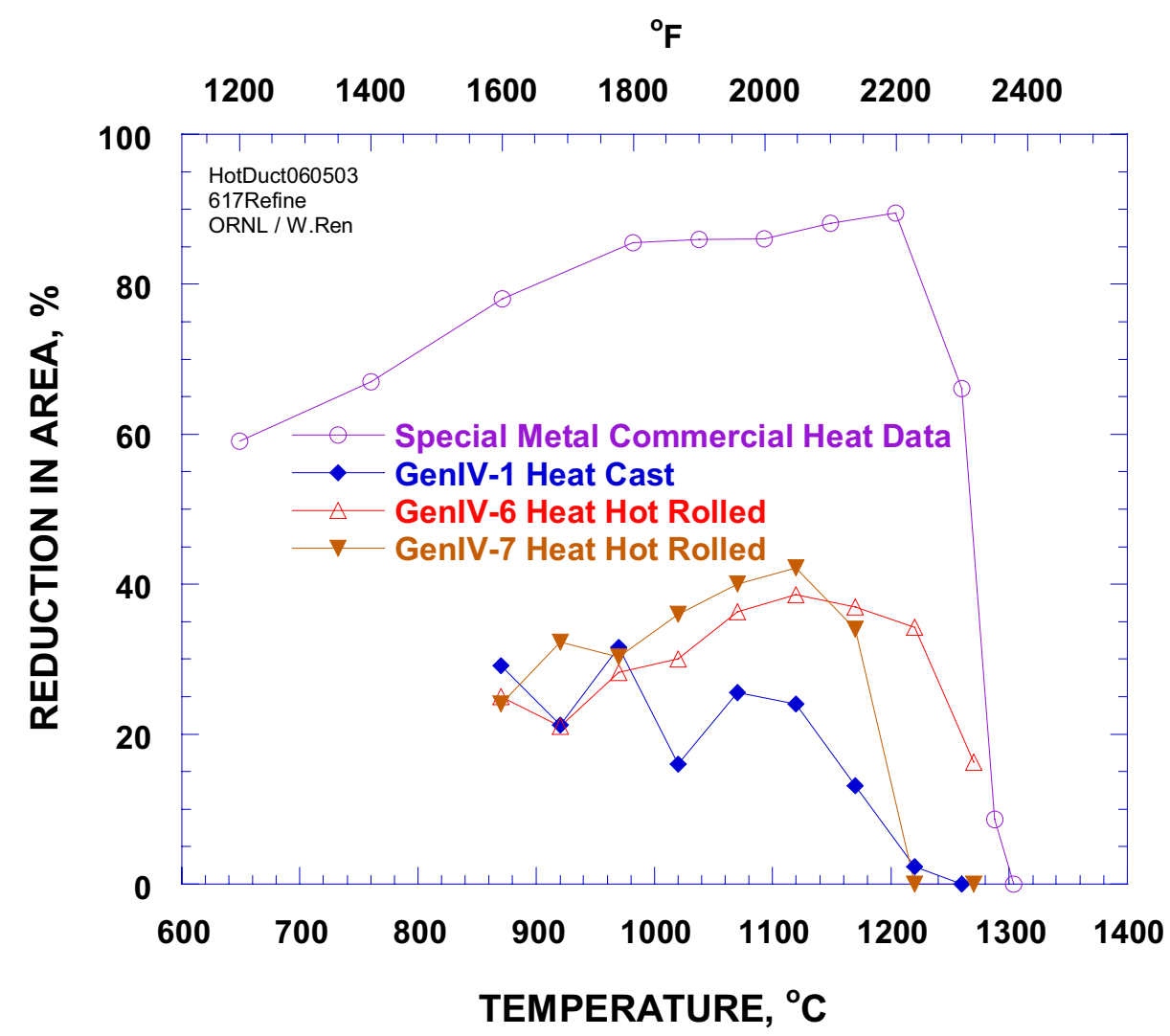

Figure 3. Hot ductility of experimental CMS 617 heats

Analysis of the results in Figure 3 also indicates that hot working, per se, may actually improve hot ductility of the material. The GenIV-6 has the average composition of 13 commercial heats; however, its hot ductility curve is significantly lower than that of the Special Metal commercial heat data. Two possibilities exist for this observation. First, some difference presently unknown might exist between the two testing procedures. To verify this speculation, a commercial heat acquired by INL in FY 2005 (Heat No. XX2834UK) has been sent for machining Gleeble specimens. Tests will be conducted to compare data from these specimens with the Special Metal commercial heat data when the specimens are ready. The second possibility, which is almost a certainty, is that the microstructures of the two heats can be very different due to processing. The Special Metal commercial heat data were produced from a plate that had experienced significant thickness reduction. As a common practice, commercial plates are normally reduced to their thicknesses from the ingot thickness range of $305 \sim 508 \mathrm{~mm}(12 \sim 20$ "), with many reheats and annealing between the passes. Whereas the total reduction of the GenIV-6 heat was only from $25.4 \mathrm{~mm}(1$ ") to $12.7 \mathrm{~mm}(0.5$ "), although it also had multiple passes with reheats in between. The difference in the hot working scope is believed to be the main cause for the significant difference observed between the Special Metal commercial heat data curve and the GenIV-6 curve. It is also believed that the cast structure of GenIV-1 is a major contributor to its lower hot ductility curve compared to that of the GenIV-6 heat with a hot rolled structure. . Understanding this is extremely important. If the refinement efforts eventually suggest a CMS 617 composition for large-scale data generation, the order size will be an important factor to consider. Product forms will also have to be carefully studied. 


\section{Summary and Future Plans}

Material for initial testing of alloy 230 and a controlled-chemistry variant of alloy 617 has been procured in the form of plates. While detailed characterization test matrices are still being developed, initial characterization of both alloys will include tensile testing at room and elevated temperatures, roomtemperature impact testing, creep testing at selected test conditions in the temperature range from 800 to $1000^{\circ} \mathrm{C}$, and low-cycle fatigue and creep-fatigue testing in the same temperature range. Deformation testing under controlled strain rates will also be performed to develop constitutive equations. This report will be updated in September 2006 to include characterization results obtained in FY 2006.

\section{References}

1. Ren, W., and R. W. Swindeman, Development of A Controlled Material Specification for Alloy 617 for Nuclear Applications, ORNL/TM-2005/504, U. S. Department of Energy Generation IV Nuclear Reactor Program, U. S. Department of Energy, May 30, 2005.

2. Ren, W., Letter to Alstom Power for CCA 617, communication between ORNL and Alstrom Power, February, 10, 2006.

3. Ren, W., and R. W. Swindeman, High Temperature Metallic Materials Test Plan for Generation IV Nuclear Reactors, ORNL/TM-2005/507, U. S. Department of Energy Generation IV Nuclear Reactor Program, U. S. Department of Energy, November 30, 2004. 